\title{
Reducing the Nitrogen Oxides Content in The Internal Combustion Engine Exhaust Gases by Using the Waste Heat Engine
}

\author{
M.L. Khasanova, M.S. Dmitriyev, V.V. Rudnev, E.P. Merkulov, V.G. Ulyanova \\ South Ural State Humanitarian Pedagogical University, Chelyabinsk, Russia
}

\begin{abstract}
This paper is dedicated to solving the problem of reducing the nitrogen oxides content in exhaust gases while ensuring internal combustion engines fuel economy.

Nitrogen oxides are the most toxic component of car exhaust. At the same time, the list of existing technologies that ensure the reduction of nitrogen oxides emissions while maintaining the engines fuel economy is very limited. Almost all the methods used to reduce the nitrogen oxides emission consist in a certain deforcing of the working process and, as a result, an increase in the specific fuel consumption.

As a solution to this problem, the authors proposed the waste heat engine with an external heat supply and internal vapor generation. This engine is based on the PD-10U (ПД-10У) two-stroke starting engine, from which standard fuel and ignition systems were dismantled. Exhaust gases enter it, they are compressed, and then water is injected. The composition of the gas-vapor mixture in the cylinders undergoes complex changes; the presence of water vapor in the system at a temperature of $1,500^{\circ} \mathrm{C}$ leads to thermal dissociation of its molecules, which makes possible to oxidize toxic components. In addition, the use of the waste heat engine allows generating additional power by utilizing the heat of the exhaust gases.
\end{abstract}

Key words: internal combustion engine, exhaust gases, toxic components, nitrogen oxides, waste heat engine, external heat supply

\section{INTRODUCTION}

The environment is exposed to the negative effects of various toxic substances of car exhaust gases, one of which is nitrogen oxides (NOx). When automobile fuel is burned, about $80 \%$ of nitrogen oxides present nitrogen monoxide (NO). The remaining 20\% is nitrogen dioxide (NO2) [1]. Nitrogen monoxide is a colorless gas. Its presence in the air (as well as carbon monoxide) is not determined by the human senses. This compound, like carbon monoxide, binds to blood hemoglobin. In this case, unstable nitrous compounds are obtained, from which methemoglobin is rapidly formed. Methemoglobin at a concentration of 60-70\% of blood is fatal.

Nitrogen dioxide (NO2) causes irritation to the respiratory mucosa. Inhalation of nitrogen dioxide toxic fumes can lead to severe poisoning. When it enters the respiratory system, $\mathrm{NO} 2$, as a result of contact with moisture, turns into nitrogen and nitric acid, which corrode the walls of the lung alveoli.

The content of these substances in the exhaust gas along with the organization of the working process, the internal combustion engine (ICE) design and characteristics depends on the operation principle, design and adjustments of the fuel equipment. At the same time, the list of existing technologies that ensure the reduction of nitrogen oxides emissions while maintaining the engines fuel economy is very limited. Almost all the methods used to reduce the emission of nitrogen oxides consist in a certain deforcing of the working process and, as a result, an increase in the specific fuel consumption.

The above allows concluding that there is a problem of increasing the engines environmental performance while ensuring the fuel economy of ICE.

\section{LITERATURE REVIEW}

Tighter environmental requirements and rising fuel costs are forcing researchers around the world to look for ways to improve the environmental friendliness and efficiency of transport engines.

One of the directions is to study the effectiveness of hybrid power plants using thermal energy that is removed to the atmosphere with the internal combustion engine exhaust gases [2-9].

The second direction explores possible ways to reduce the internal combustion engines harmful effects on humans and the environment. The range of these problems is wide. It includes reducing toxicity of exhaust gases, noise and vibration effects on the biosphere, reducing the greenhouse effect, questions related to the disposal of automotive maintenance materials and much more [10-14].

But a comprehensive solution to these problems that combines both of the directions, which has been worked out to the end, does not currently exist. In this regard, the authors 
propose one of the ways to increase both the efficiency and environmental friendliness of the internal combustion engine, which is the use of waste heat engine.

\section{PROPOSED METHODOLOGY}

\subsection{General description}

In order to reduce the nitrogen oxides content in the internal combustion engine exhaust gases, the authors of this paper carried out theoretical studies, developed a power plant with a waste heat engine, conducted a series of experiments and processed experimental data (table 1).

\subsection{Algorithm}

After theoretical research, the power plant, consisting of a KamAZ-740 diesel engine of a serial design and a waste heat engine with an external heat supply and internal vapor generation, was developed.

The first stage of experimental research was to determine the influence of various factors on the changes in the nitrogen oxides content in the exhaust gases.

When planning this experiment, the task was to define a mathematical model in the form of a second-order equation that adequately describes the change of nitrogen oxides content as a function of five factors. To determine the control coefficients, the Hartley's experimental hypercube plan was implemented.

According to the experiment plan, 27 experiments were conducted. To eliminate random errors, each experiment was performed three times. To reduce systematic errors, experiments were performed in a random order using a random numbers table.

At the second stage, the change in the nitrogen oxides content in power plant's various operation modes was evaluated. The nitrogen oxides content in the exhaust gases was determined using the infrared multichannel gas analyzer INFRALYT-4000.

During the experimental data processing, after testing the dispersion homogeneity hypothesis (Cochran's $\mathrm{C}$ test was used for this, taking the significance level $q=5 \%$, the degrees of freedom number $V_{1}=m-1=2$ and $V_{2}=N=27$ ), the reproducibility dispersion and mean square experimental error were determined by the known formulas.

The regression equations coefficients were calculated using the formulas for second-order plans. After calculating the coefficients, they were checked for statistical significance using Student's t-test. In order to exclude the statistically insignificant coefficients, a sequential regression analysis was performed.

The adequacy of the model was tested using the Fisher's ratio test. To test the model adequacy hypothesis, the significance level was set to $q=5 \%$, the degrees of freedom number $V_{1}=N-1$ and $V_{2}=N(m-1)$.

\subsection{Flow Chart}

Table 1: Research algorithm

\begin{tabular}{|l|l|}
\hline № & Name of the research phase \\
\hline 1 & Theoretical research \\
\hline 2 & Development of a power plant with a waste heat engine \\
\hline 3 & Experimental studies \\
\hline 3.1 & $\begin{array}{l}\text { First stage. Determination of the influence of various } \\
\text { factors on the changes in the nitrogen oxides content }\end{array}$ \\
\hline 3.2 & $\begin{array}{l}\text { Second stage. Determination of the change in the } \\
\text { nitrogen oxides content in power plant's various } \\
\text { operation modes }\end{array}$ \\
\hline 3.3 & Experimental data processing \\
\hline
\end{tabular}

\section{RESULT ANALYSIS}

\subsection{Theoretical research}

The conversion of the burned fuel heat into engine operation is associated with significant energy losses. This primarily relates to heat loss with exhaust gases emitted into the atmosphere. It is known that up to $70 \%$ of energy is emitted from engines into the atmosphere, which indicates a significant thermal potential of exhaust gases.

The use of this energy can be carried out by utilizing various engines with external heating and thermoelectric generators [15]. One of the options for a heat, lost from exhaust gases, recovery system is an engine with an external heat supply [16-18].

Exhaust gases enter it, they are compressed, and then water is injected. Calculations showed that the temperature at the end of compression can reach $1500{ }^{\circ} \mathrm{C}$ and higher. Sprayed water under these conditions evaporates strongly, producing useful work. This additional work increases the overall power of the power plant (including ICE and a waste heat engine). At the indicated temperatures, the composition of the gas-vapor mixture in the cylinders undergoes complex changes; the presence of water vapor in the system at a temperature of $1500{ }^{\circ} \mathrm{C}$ leads to thermal dissociation of its molecules, which makes possible to oxidize exhaust gases' toxic components.

Thus, a whole range of tasks is being solved, along with the additional power generation, as well as the exhaust gases toxicity reduction.

The following characteristics can be used to evaluate the effectiveness of exhaust gases toxicity reducing as a result of any measures (in this case, when using a waste heat engine):

- indicator of changes in toxicity of the i-th component:

$$
C_{i}^{*}=\frac{C_{i}^{w h}}{C_{i}^{d}},
$$

where $C_{i}^{d}$ and $C_{i}^{w h}$ - emissions of the i-th component during the operation of a diesel engine without waste heat engine and with it, respectively; 
degree of decrease in the i-th toxic component concentration:

$$
\Delta C_{i}=1-\frac{C_{i}^{w h}}{C_{i}^{d}}
$$

The above indicators give an idea of the toxic substances content in the exhaust gases only in one operating mode of the power plant. To assess the neutralization effectiveness in all modes in a comprehensive manner, these indicators are more logical to consider in the form of integral characteristics, taking into account the piston engine operating modes distribution.

Then indicators (1) and (2) will get the meaning of operational ones:

operational indicator of changes in toxicity of the i-th component:

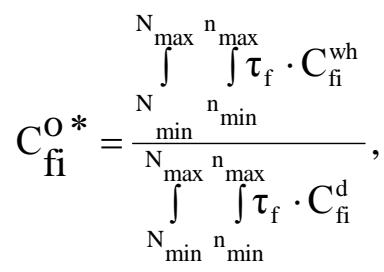

where $N_{\text {min }}$ and $N_{\text {max }}$ - minimum and maximum engine power, respectively, $n_{\min }$ and $n_{\max }$ - minimum and maximum engine speed, respectively, ${ }^{\tau_{f}}$ - duration of the f-th mode of operation, $C_{f i}^{d}$ and $C_{f i}^{w h}$ - emissions of the i-th component at the $f$-th mode of operation of a diesel engine without waste heat engine and with it, respectively;

- operational degree of decrease in the $\mathrm{i}$-th toxic component concentration:

$$
\Delta C_{f i}^{o}=1-C_{f i}^{o *}
$$

\subsection{Structure and operation of the device}

The developed power plant consists of a KamAZ-740 diesel engine of a serial design and a waste heat engine with an external heat supply and internal vapor generation. This engine is based on the PD-10U (ПД-10У) two-stroke starting engine, from which standard fuel and ignition systems were dismantled [19]. Schematic diagram of the waste heat engine with an external heat supply and internal vapor generation is shown in fig. 1.

The base of the engine is the crankcase 1, consisting of two parts interconnected by bolts. The cylinder 4 , closed on top by a head 6 , is mounted on the crankcase with threaded rods and nuts. There are two windows 3 and 7 in the cylinder on the flywheel side, one of which (inlet) is connected to the KamAZ-740 diesel engine exhaust pipe, and the other (outlet) is connected to the waste heat engine exhaust pipe 8 , through which gases leaving the waste heat engine cylinder enter the condenser 9 , cooled by running water. Here the vapors condense and separate from the gases that are piped into the atmosphere. The resulting condensate can be reused to power the waste heat engine.

The cylinder outlet window is additionally bored vertically and begins to open with the piston top edge when it moves to the bottom dead center (BDC) a little earlier than the inlet window. Thus, a more effective cleaning of the cylinder from exhaust gases is carried out.

The remaining windows that were in the standard cylinder of the PD-10U engine are closed off.

A piston 2 having a spherical bottom is mounted so that the compression rings' joints do not fall into the cylinder windows, thereby preventing rings breakage.

The connecting rod has one-piece heads. A bronze bushing is pressed in the upper head, and a roller bearing is mounted in the lower one.

The crankshaft is compound, assembled with the connecting rod and bearing. It is supported by two roller bearings and is kept from longitudinal movements by an additional support. The crankshaft outputs from the crankcase are sealed with rubber gaskets, and the rear output is sealed also with a felt one.

Since the fuel mixture does not enter the crankcase during operation of the waste heat engine, oil is poured into it; by spraying this oil, the parts of the crank mechanism are lubricated. 


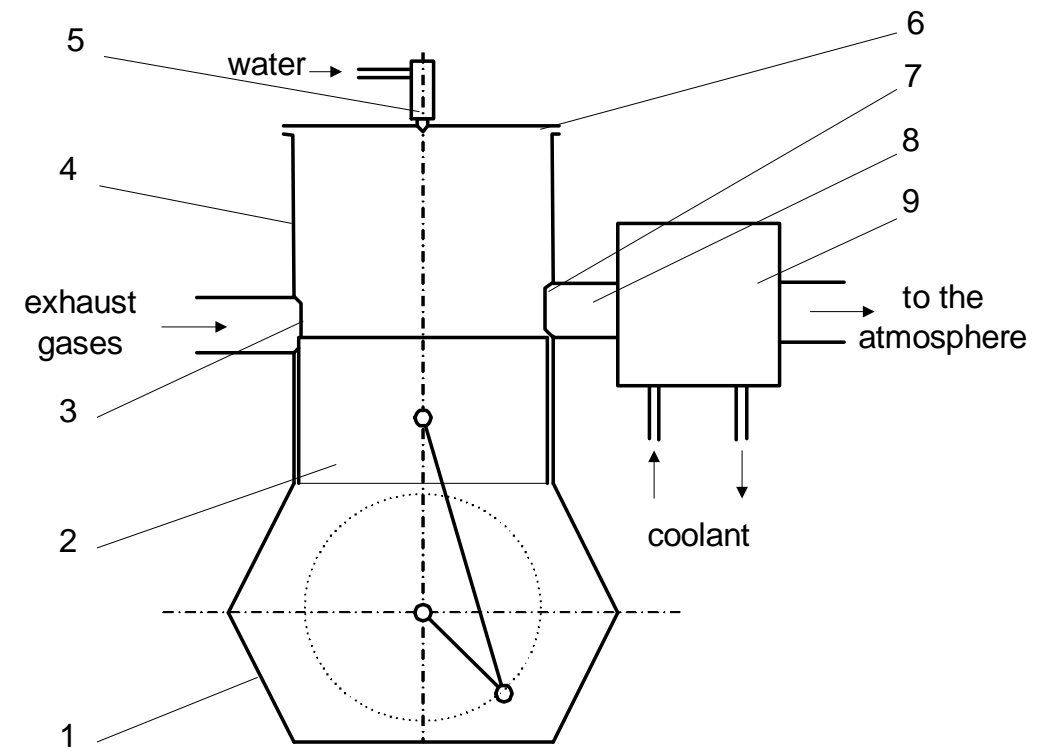

Figure 1: Schematic diagram of the waste heat engine with an external heat supply and internal vapor generation:

1 - crankcase; 2 - piston; 3 - inlet window; 4 - cylinder; 5 - injector; 6 - head; 7 - outlet window; 8 - exhaust pipe; 9 - condenser

In the cylinder cooling system cavity that is not filled with liquid, nichrome spirals are installed to heat its walls.

An experimental cylinder head (instead of the standard one) provides a reduction in the volume of the compression chamber, which increases the geometric compression ratio to 11.0. The two holes in the head are for mounting the nozzle and piezoelectric pressure sensor.
The water supply system includes parts and mechanisms that provide the necessary water pressure and its entry into the waste heat engine cylinder at the required moment of the engine operating cycle [20]. It consists of the reservoir 1 with compressed air, pressure regulator 2, pipeline 4 connecting the air reservoir to the reservoir 3 filled with water, pipeline 7 connecting the water reservoir to the injector 8 (fig. 2).

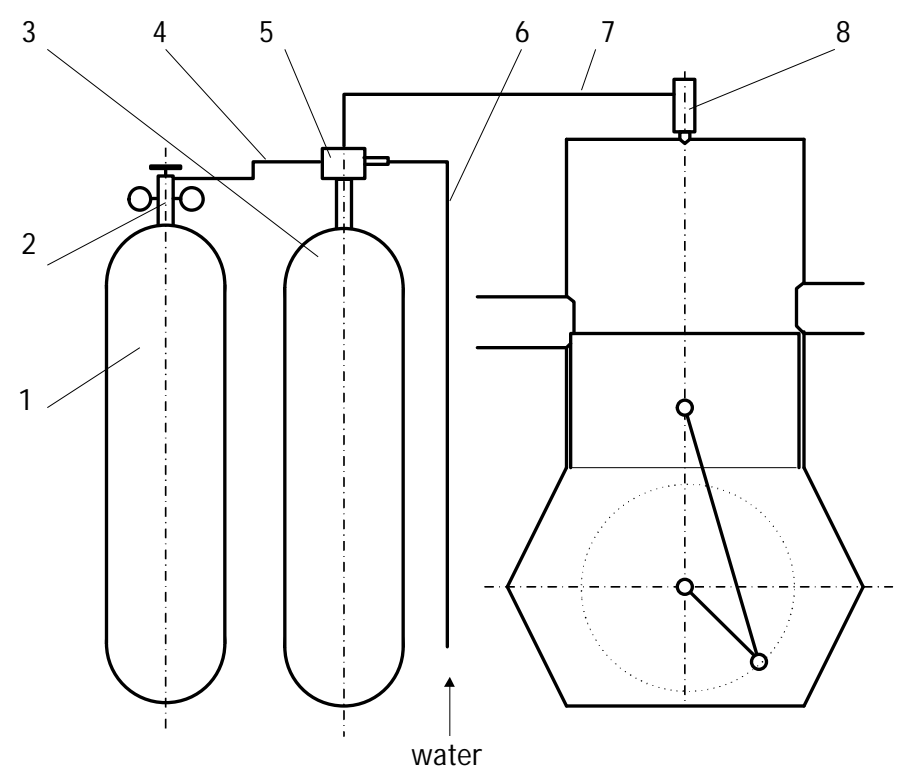

Figure 2: Schematic diagram of the waste heat engine water supply system:

1 - air reservoir; 2 - pressure regulator; 3 - water reservoir; 4 - air pipeline; 5 - fitting; 6 - feed pipeline; 7 - delivery pipeline; 8 injector

The water reservoir 3 is equipped with a triple fitting 5, through one channel of which compressed air is supplied to this reservoir, through another, water under pressure, created by the compressed air, enters the injector. The third channel with a reverse valve provides periodic water pumping through the pipeline 6 into the reservoir 3 as it is spent. In the process of the waste heat engine operation, the air from the reservoir 1 through the pipe 4 constantly enters the water reservoir 3 
under a constant pressure supported by the pressure regulator 2. Under the same pressure, the water through the pipe 7 continuously goes to the injector 8 , which has holes closed by a shut-off needle, pressed against the seating by a spring.

The unit works as follows. At the moment when the piston moves from the top dead center (TDC) to the BDC, its upper edge begins to open the inlet window 3 (see fig. 1), the hot exhaust gases of the diesel engine enter the intracylinder volume. The filling of the cylinder with gases continues as the piston 2 moves to the BDC and when it moves back from the BDC to the TDC until the top edge of the piston overlaps the inlet window 3. Then, as soon as the outlet window is also blocked, the compression of the diesel exhaust gas entering the cylinder begins.

In the process of compression, the temperature of the working fluid (initially hot) increases significantly. When the piston approaches TDC, water is injected into the cylinder through the injector 5 . Intensive vapor generation occurs. The vapor expands, producing work. As soon as the bottom of the piston 2 begins to open the outlet window 7 , the working fluid exits the cylinder 4 as a result of the difference in the intracylinder pressure and the pressure in the waste heat engine exhaust system, and after opening the inlet windows also by blowing the cylinder with diesel exhaust. Then the cycle repeats.
In the present work, the dependence of the degree of decrease in the nitrogen oxides concentration from five following factors was established:

1. The exhaust gases temperature ( $\left.T_{E G}\right)$ at the entrance to the waste heat engine cylinder;

2. Temperature of the waste heat engine cylinder's inside walls $\left(T_{W}\right)$;

3. Pressure of water injection into the waste heat engine cylinder $\left(P_{w i}\right)$;

4. Duration of water injection into the waste heat engine cylinder in degrees of crankshaft rotation $(\varphi)$;

5. Moment of water injection beginning in degrees of crankshaft rotation relative to the top dead center $(\theta$ ).

$$
y=b_{0}+\sum_{i=1}^{k} b_{i} x_{i}+\sum_{i \neq j}^{k} b_{i j} x_{i} x_{j}+\sum_{i=1}^{k} b_{i i} x_{i}^{2}
$$

where $b_{0}, b_{i}, b_{i j}, b_{i i}$ - coefficients of the mathematical model $k$ - number of the mathematical model elements; $x_{i \text { and }} x_{j}$-factor values.

The accepted variation levels and intervals of all factors are presented in table 2 .

\subsection{Experimental studies}

Table 2: Factors' variation levels and intervals

\begin{tabular}{|c|c|c|c|c|c|c|c|}
\hline \multicolumn{4}{|l|}{ Factors } & \multicolumn{4}{|c|}{ Variation levels } \\
\hline \multirow{3}{*}{ Name } & \multirow{3}{*}{$\begin{array}{c}\text { Units } \\
\text { measure }\end{array}$} & \multicolumn{2}{|l|}{ Symbol } & \multicolumn{3}{|c|}{ Code mark } & \multirow{3}{*}{$\begin{array}{l}\text { Variation } \\
\text { intervals }\end{array}$} \\
\hline & & In kind & Code & -1 & 0 & 1 & \\
\hline & & & mark & \multicolumn{3}{|c|}{ In kind } & \\
\hline $\begin{array}{l}\text { I. Exhaust gases } \\
\text { temperature }\end{array}$ & ${ }^{\circ} \mathrm{C}$ & $T_{E G}$ & $\mathrm{X}_{1}$ & 450 & 650 & 850 & 400 \\
\hline $\begin{array}{c}\text { Temperature of the } \\
\text { cylinder's inside walls }\end{array}$ & ${ }^{\circ} \mathrm{C}$ & $T_{W}$ & $\mathrm{X}_{2}$ & 80 & 115 & 150 & 70 \\
\hline Water injection pressure & $\mathrm{MPa}$ & $P_{w i}$ & $\mathrm{X}_{3}$ & 5 & 10 & 15 & 10 \\
\hline $\begin{array}{c}\text { Duration of water } \\
\text { injection }\end{array}$ & $\begin{array}{l}\quad \text { degrees of } \\
\text { crankshaft } \\
\text { rotation }\end{array}$ & $\varphi$ & $\mathrm{X}_{4}$ & 5 & 15 & 25 & 20 \\
\hline $\begin{array}{c}\text { Moment of } \\
\text { injection beginning }\end{array}$ & $\begin{array}{l}\quad \text { degrees of } \\
\text { crankshaft } \\
\text { rotation }\end{array}$ & $\theta$ & $\mathrm{X}_{5}$ & $\begin{array}{l}10 \text { to } \\
\text { TDC }\end{array}$ & $\begin{array}{l}5 \text { to } \\
\text { TDC }\end{array}$ & $\begin{array}{l}0 \\
(\mathrm{TDC})\end{array}$ & 10 \\
\hline
\end{tabular}

As a result of processing the experimental data, the following

polynomial dependence was found:

$$
\begin{aligned}
& \Delta C_{N O_{X}}=0,1835-0,1 X_{1}-0,02 X_{2}+0,12 X_{3}+0,1 X_{4}+0,01 X_{5}+0,09 X_{4}^{2}+0,0026 X_{1} X_{3}+ \\
& +0,0047 X_{2} X_{3}-0,034 X_{3} X_{5}
\end{aligned}
$$


The results of the second stage of experimental studies, consisting in determination of the change in the nitrogen oxides content in power plant's various operation modes, showed the following.

The nitrogen oxides content in diesel exhaust without the waste heat engine was $9.30 \mathrm{~g} / \mathrm{m}^{3}\left(\right.$ at $\left.\mathrm{n}=1000 \mathrm{~min}^{-1}\right), 11.8$ $\mathrm{g} / \mathrm{m}^{3}\left(\right.$ at $\left.\mathrm{n}=1800 \mathrm{~min}^{-1}\right)$ and $10.60 \mathrm{~g} / \mathrm{m}^{3}\left(\right.$ at $\left.\mathrm{n}=2600 \mathrm{~min}^{-1}\right)$. It decreases as a result of the waste heat engine application to $7.00 \mathrm{~g} / \mathrm{m}^{3} ; 9.00 \mathrm{~g} / \mathrm{m}^{3}$ and $8.20 \mathrm{~g} / \mathrm{m}^{3}$ or $26.0 \% ; 23.7 \%$ and $22.0 \%$, respectively. The intensity of the almost monotonic nitrogen oxides content decrease in emissions after waste heat engine compared to their amount in diesel exhaust gases was on average $0.25 \%$ for every $100 \mathrm{~min}^{-1}$.

The nature of the established trend is obviously connected with the fact that nitrogen oxides in the process of reaction with water vapor turn into nitric and nitrous acids and are "carried out" from the exhaust gas stream with condensate.

\section{CONCLUSION}

The research results and their analysis allow us to draw the following conclusions.

The greatest decrease in the nitrogen oxides concentration during the exhaust gases heat utilization was observed at low loads and at low engine speeds, since it was with them that the minimum amount of NOx exited the standard engine cylinder, and the water entering the waste heat engine performed the neutralization function most successfully.

This is confirmed by the results of the condensate chemical analysis, in which there was practically no change in the nitric and nitrous acids content in the samples taken at different frequencies of rotation of the diesel engine crankshaft. The above indicates a sufficiently high efficiency of exhaust gases toxicity reducing using the developed device. Thus, the claimed technical solution allows increasing the ICE environmental friendliness by reducing the nitrogen oxides content in the exhaust gases without affecting the main engine operation. In addition, its use makes it possible to generate additional power by utilizing the exhaust gases heat.

\section{ACKNOWLEDGEMENT}

The authors express their gratitude to The South Ural State University (National Research University) and South Ural State Technical College for providing material resources for research work.

\section{REFERENCES}

1. V.A. Likhanov, O.P. Lopatin. Investigation of nitrogen oxides in the cylinder of a gas-diesel engine. International Scientific Conference «Metrological Support of Innovative technologies - ICMSIT-2020», 2020.

2. G. Fontaras, P. Pistikopoulos, Z. Samaras. Experimental evaluation of hybrid vehicle fuel economy and pollutant emissions over real-world simulation driving cycles. Atmospheric Environment, no. 18 , pp. 4023-4035, 2008.

3. M. Valenti. Hybrid car promises high performance and low emissions. Mecanical Engineering, no. 7, pp. 46-49, 1994.

4. A.D. Jazcilevich, A.G. Reynoso, M. Grutter, J. Delgado, M.S. Lastra, R.G. Oropeza, M. Zuk, U.D. Ayala, J. Lents, N. Davis. An evaluation of the hybrid car technology for the Mexico mega city. Journal of Power Sources, vol. 196, no. 13, pp. 5704-5718, 2011.

5. S. Ashley. A hybrid concept car. Mecanical Engineering, no. 4, 10-11, 1998.

6. E. Teriaeva. The research of electromagnetic fields during testing of a hybrid power plant and a hybrid car prototype. Lecture Notes in Electrical Engineering, no. 3, pp. 509-518, 2013.

7. V.S. Kukis, E.A. Omelchenko, A.V. Raznoshinskaia. Results of vortex tube usage in diesel exhaust gas recirculation system. Procedia Engineering, no. 129, pp. 151-155, 2015.

8. A.V. Raznoshinskaia. Results of vortex tube usage in diesel exhaust gas recirculation system. Procedia Engineering, no. 129, pp. 140-144, 2015.

9. A. Gritsenko, S. Kukov, K. Glemba. Theoretical underpinning of diagnosing the cylinder group during motoring. Procedia Engineering, no. 150, pp. 1182-1187, 2016.

10. S.G. Poulopoulos, D.P. Samaras, C.J. Philippopoulos. Regulated and unregulated emissions from an internal combustion engine operating on ethanol-containing fuels. Atmospheric Environment, no. 26, pp. 4399-4406, 2001.

11. D. Strzelecki. Internal combustion engine units treat soil vapor gas. Pollution Engineering, no. 9, p. 61, 2000.

12. S.G. Poulopoulos, D.P. Samaras, C.J. Philippopoulos. Regulated and speciated hydrocarbon emissions from a catalyst equipped internal combustion engine. Atmospheric Environment, no. 26, pp. 4443-4450, 2001.

13. E. Pervukhina, K. Osipov, V. Golikova. Lowering toxic concentrations in the diesel exhaust gases. Communications in Computer and Information Science, no. 499, pp. 118-128, 2015.

14. O. Klyus. Simultaneous reduction of fuel consumption and toxic emission of exhaust gases of high speed diesel engines. 17-th International Multidisciplinary Scientific Geoconference - SGEM-2017, pp. 801-808, 2017.

15. E. Massaguer, T. Pujol, M. Comamala, L. Montoro, J.R. Gonzalez, A. Massaguer. Fuel economy analysis under a WLTP cycle on a mid-size vehicle equipped with a thermoelectric energy recovery system. Energy, no. 179, 306-314, 2019. https://doi.org/10.1016/j.energy.2019.05.004

16. M. Chinnapandian, V. Pandiyarajan, A. Prabhu, R. Velraj. Experimental investigation of a cascaded latent heat storage system for diesel engine waste heat recovery. Energy Sources. Part A: Recovery, 
M.L. Khasanova et al., International Journal of Emerging Trends in Engineering Research, 8(8), August 2020, 4537 - 4543

Utilization, and Environmental Effects, vol. 37, no. 12, pp. 1308-1317, 2015.

17. M.R. Wilson John. L.R. Ganapathy Subramanian. Performance analysis of custom-designed heat exchanger and latent heat thermal energy storage system for diesel engine exhaust waste recovery system. Iranian Journal of Science and Technology Transaction of Mechanical Engineering, vol. 43, no. Suppl. 1, pp. 679-694, 2019

18. M. Hamdy, K. Harby, N. Kora, A.A. Askalany. An overview on adsorption cooling systems powered by waste heat from internal combustion engine. Renewable and Sustainable Energy Reviews, no. 51, 1223-1234, 2015.

19. V.V. Rudnev, M.S. Dmitriyev, M.L. Khasanova, E.P. Merkulov, V.G. Ulyanova. Pneumatic Hybrid Power Plants Efficiency. International Journal of Engineering and Advanced Technology, vol. 8, no. 6, pp. 5186-5191, 2019.

20. M.S. Dmitriyev, M.L. Khasanova, A.V. Raznoshinskaya. Substantiation of hydraulic system for weighing freights transported with dump trucks. Procedia Engineering, no. 206, pp. 1604-1610, 2017. https://doi.org/10.1016/j.proeng.2017.10.685 